\title{
Epidemiology of Childhood Brain Tumors
}

\author{
Darlene Miltenburg, Deon F. Louw and Garnette R. Sutherland
}

\begin{abstract}
Background: Brain tumors comprise more than 20\% of all childhood malignancies, and constitute the greatest number of solid pediatric cancers. Incidence rates reported have varied from 2.4 to $3.5 / 100,000$ children, reflecting the impact of modern imaging techniques, the application of diverse investigative methodologies, and the accessibility of the community to health care. Methods: Material from patients < 18 years of age was collated from the Manitoba Cancer Foundation Tumor Registry, the personal records of Winnipeg pediatric neurologists, and autopsy data. Patient data were also obtained from hospital charts and operating room log books. Histological sections were examined and classified according to the American Cancer Society by a single neuropathologist. The chi-square test was used for statistical evaluation. Results: During the seven-year study period, the diagnosis of brain tumor was made in 89 pediatric patients, of which 88 were diagnosed premortem. The overall average annual incidence rate for both sexes was $4.03 / 100,000$ child-years, higher than that previously reported. The male and female average annual incidence rates were 4.2 and $3.7 / 100,000$ child-years, respectively. Tumor type and location were relatively unremarkable, with an expected peak of medulloblastoma occurring in young males. The yearly incidence of tumor occurrence was fairly stable, and the geographic distribution of cases within Manitoba, homogeneous. Conclusion: The highest incidence rates of pediatric brain tumors have been recorded in countries possessing sophisticated universal health care systems, possibly reflecting their efficacy in disease surveillance.
\end{abstract}

RÉSUMÉ: Épidémiologie des tumeurs cérébrales de l'enfant. Introduction: Plus de $20 \%$ des cancers chez l'enfant sont des tumeurs cérébrales et ces tumeurs représentent le plus grand nombre des cancers pédiatriques solides. Les taux d'incidence rapportés varient entre 2.4 et 3.5/100,000 enfants, reflétant l'impact des techniques d'imagerie moderne, l'application de méthodes d'investigation variées et l'accessibilité des soins de santé communautaires. Méthodes: Nous avons compilé les données concernant les patients de moins de 18 ans du Régistre des tumeurs de la Fondation du cancer du Manitoba, des dossiers personnels des neurologues pédiatriques de Winnipeg ainsi que des données d'autopsies. Des données concernant les patients ont également été obtenues des dossiers hospitaliers des patients ainsi que des cédules opératoires. Les coupes histologiques ont été examinées et classifiées par le même neuropathologiste selon la classification de la Société américaine du cancer. Le chi-carré a été utilisé comme épreuve statistique. Résultats: Pendant les sept ans de l'étude, le diagnostic de tumeur cérébrale a été posé chez 89 enfants, dont 88 diagnostics prémortem. Le taux d'incidence annuel moyen pour les deux sexes était de $4.03 / 100,000$ enfant-années, ce qui est supérieur au taux rapporté antérieurement. Les taux d'incidence annuels moyens pour les garçons et les filles respectivement étaient de 4.2 et de 3.7/100,000 enfant-années. Les tumeurs étaient relativement communes quant au type et à la localisation, avec un pic pour le médulloblastome chez les jeunes garçons. L'incidence annuelle des tumeurs était plutôt stable et la distribution géographique des cas était homogène sur le territoire du Manitoba. Conclusion: Les plus hauts taux d'incidence de tumeurs cérébrales pédiatriques ont été rapportés dans les pays possédant un système de soins de santé universel sophistiqué, ce qui reflète une surveillance efficace de la maladie.

Can. J. Neurol. Sci. 1996; 23: 118-122

Brain tumors constitute the greatest number of solid childhood cancers, and comprise more than $20 \%$ of all childhood malignancies. Pediatric brain tumors are thus of obvious epidemiologic significance, and a variety of relevant reports exists. ${ }^{1-14}$ Their incidence rates have been variously determined to be between 2.4 and 3.5 per 100,000 children, utilizing different techniques and sources. Data accrual has been based on tumor registries, hospital referral patterns and other methodologies, and this is reflected in the discordance of results. Incongruous histologic classification schemes have been applied, and it is only fairly recently that attempts have been made to rationalize parameters of tumor definition. ${ }^{15}$ An additional complicating variable is the recent advent of advanced neuroimaging technology and its effect on the sensitivity and specificity of brain tumor diagnosis.

We elected to investigate the epidemiology of childhood brain tumors in Manitoba as a community-based phenomenon,

\footnotetext{
From the Department of Surgery, University of Manitoba, Winnipeg (D.M.), and Department of Clinical Neurosciences, University of Calgary, Calgary (D.F.L.,G.R.S.), RECEIVED FEBRUARY 24, 1995. ACCEPTED IN FINAL FORM OCTOBER 20, 1995. Reprint requests to: Dr. Garnette Sutherland, Department of Clinical Neurosciences, Foothills Hospital, 1403 - 29 Street N.W., Calgary, Alberta, Canada T2N 2T9
} 
thus eliminating the bias inherent to referral-based studies. The demographic characteristics of Manitoba are ideal for such scrutiny, as it is a stable population with minimal migration flux. All brain tumor patients in Manitoba are assessed in a single city at one of three facilities, ensuring faithful statistical capture. All children diagnosed with cancer, for example, are routinely registered at the Manitoba Cancer Foundation. The purpose of this study was thus to precisely define the age-specific incidence and the epidemiology of pediatric brain tumors in Manitoba over the seven year period from 1986 through 1992. We were also motivated by the assumption that accurate biomedical statistics have become an economic imperative in this era of fiscal constraint, and that our study would facilitate the implementation of efficient health care planning in the realm of pediatric neurosurgery.

\section{Materials and Methods}

\section{Material}

In this study, intracranial neoplasm was defined as all benign and malignant primary tumors of the brain and cranial meninges. This did not include metastatic brain tumors, retinoblastoma, or spinal cord tumors. To be included in the study, a patient must have been a resident of Manitoba at the time of diagnosis and $<18$ years of age.

Patient data were obtained from hospital charts and operating room log books from the three Manitoba referral hospitals: Health Sciences Centre, Children's Hospital, and St. Boniface General Hospital. Material was also collected from the Manitoba Cancer Foundation Tumor Registry and from the personal records of Winnipeg pediatric neurologists. In addition, data collection was also obtained from autopsy material. Any child who dies in Manitoba is reported to the Coroner and the majority undergo postmortem examination. Four hundred and thirty autopsies performed over the study interval were reviewed.

\section{Population}

Population statistics were provided by the Manitoba Centre for Health Policy and Evaluation. The Manitoba population is comprised mainly of ethnic groups of European, Slavic, Asiatic, American Indian and Inuit origin. The population has equal access to health care facilities through government-sponsored universal health care. The total population (Mean \pm SEM) has remained constant at approximately one million [1043.3 $\pm 2.8 \mathrm{x}$ $10^{3} \mathrm{~J}$ and the average annual number of children in Manitoba is $314,977 \pm 488$. The average annual number of children in various age groups is presented in Table 1. The male to female ratio is $1.05: 1$.

\section{Methods}

There were 89 children with central nervous system tumors. Their charts and radiological data were reviewed. All but one patient had computed tomography and/or magnetic resonance imaging performed at the time of diagnosis. The remaining case was defined at autopsy. Histological sections were examined by a single neuropathologist and classified according to the American Cancer Society criteria in $88 \%$ of the cases, ensuring statistical fidelity. In the remainder, diagnosis was made according to radiological characteristics and the patients' clinical course, particularly in the case of optic and brainstem glioma.
Table 1: Population Statistics - Province of Manitoba by Age.

\begin{tabular}{cc}
\hline Age Group (years) & $\begin{array}{c}\text { Average Annual } \\
\text { Number of Children }\end{array}$ \\
\hline$<1$ & 17,191 \\
$1-4$ & 67,987 \\
$5-9$ & 82,019 \\
$10-14$ & 80,507 \\
$15-18$ & 67,273 \\
\hline
\end{tabular}

Cases were compared by incidence rate per patient-year according to age, sex, diagnosis, geographic region in the province, tumor location, and tumor type. The chi-square test was used for statistical evaluation.

\section{Results}

\section{Incidence and Age and Sex Distributions}

During the seven year study period, the diagnosis of pediatric brain tumor was made in 89 patients. The Tumor Registry provided $61 \%$ of the total cases. Autopsy material added only one additional case, that of a one-year old male with a supratentorial oligodendroglioma. There were 49 males (55\%) and 40 females $(45 \%)$. The overall average annual incidence rate for both sexes was $4.03 / 100,000$ child-years with male and female average annual incidence rates of $4.2 / 100,000$ and $3.7 / 100,000$ respectively. The average annual incidence rate for childhood brain tumors by age and sex is shown in Figure 1. The most noteworthy feature of the incidence curves is the appearance of a significant peak for males in the 5 - 9 year age group, and is a phenomenon of the medulloblastoma cluster that characterizes this category. The yearly incidence of tumor occurrence was stable (Figure 2). Additionally, the geographic distribution of cases within Manitoba was noted to be fairly homogeneous, with no significant regional difference (Figure 3).

\section{Pathology}

Compartmental tumor distribution was symmetric: 45 supratentorial lesions, 43 infratentorial lesions and one case of doublecompartment tumor. Low grade astrocytoma, high grade

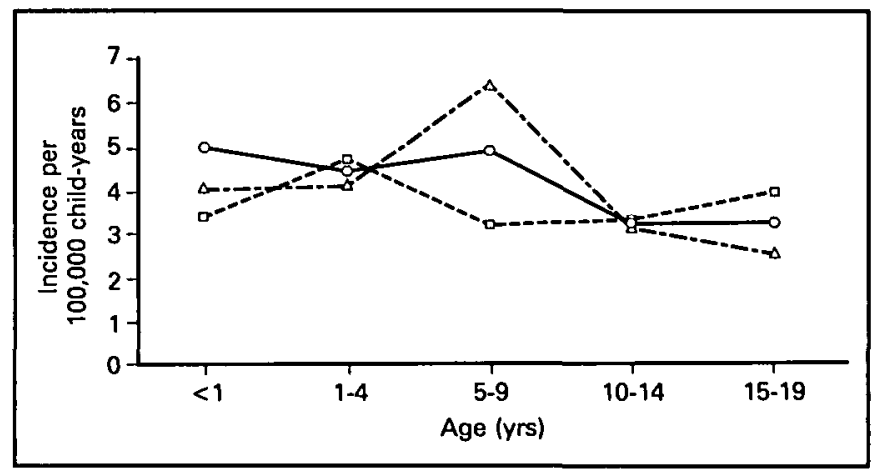

Figure 1: Average Annual Incidence Rates for Pediatric Brain Tumors by Age and Sex Males $(\triangle)$; Females $(\square)$;Both Sexes $(0)$. Males show a peak in the 5-9 year age group which is predominantly a phenomenon of medulloblastoma. 




Figure 2: Yearly Incidence of Childhood Brain Tumors from 1986 through 1992. The occurrence of annual fluctuations is not unexpected and its statistical impact is reduced by the long term nature of this study.

astrocytoma and medulloblastoma were the most commonly diagnosed lesions. A moderate number of other glial tumors and craniopharyngiomas occurred, but meningiomas, schwannomas and germ cell tumors were rarely seen (Table 2). A statistically significant relationship $(\mathrm{p}<0.001)$ of location and pathology existed, especially for midline cerebellum and medulloblastoma in contrast to lateral cerebellum and astrocytoma. There was also a significant gender correlation for pathology, where males suffered disproportionately from medulloblastoma $(p<0.049)$.

\section{Discussion}

We estimate that greater than $98 \%$ of all pediatric brain tumors diagnosed pre- and postmortem in Manitoba during the years 1986 through 1992 have been identified in this study. It is feasible that some tumors would have been diagnosed outside Manitoba and would therefore not be included. The number would, however, be small since most patients are initially reviewed in Winnipeg prior to possible referral elsewhere and would thus have undergone neuroimaging and/or have been registered with the Central Tumor Registry of Manitoba. Although obligatory postmortem examination is not the practice in Manitoba, all pediatric deaths are reported to the Medical Examiner and it is unlikely that an unexplained pediatric death would not have been further defined.

The incidence of childhood brain tumors in Manitoba (4.03/100,000 child-years) is higher than that previously reported, substantially so compared to some studies. This is particularly true of the investigations based on tumor registries, which are frequently limited to the recording of malignant cases only. Additional data sources should be utilized, as reliance on Manitoba's Central Cancer Registry alone would have reduced our case ascertainment by virtually $40 \%$. It is crucial to include both benign and malignant histologies in brain tumor epidemiology, as the designation benign uncommonly correlates with a corresponding clinical outcome. This is especially valid in the case of supratentorial glioma, which may relentlessly insinuate itself into non-resectable brain regions.

The relatively even distribution of tumor incidence throughout the Province of Manitoba is notable. This implies a paucity of toxic, tumorigenic factors in local environments. ${ }^{16}$ It also confirms the accessibility of the universal health care system,

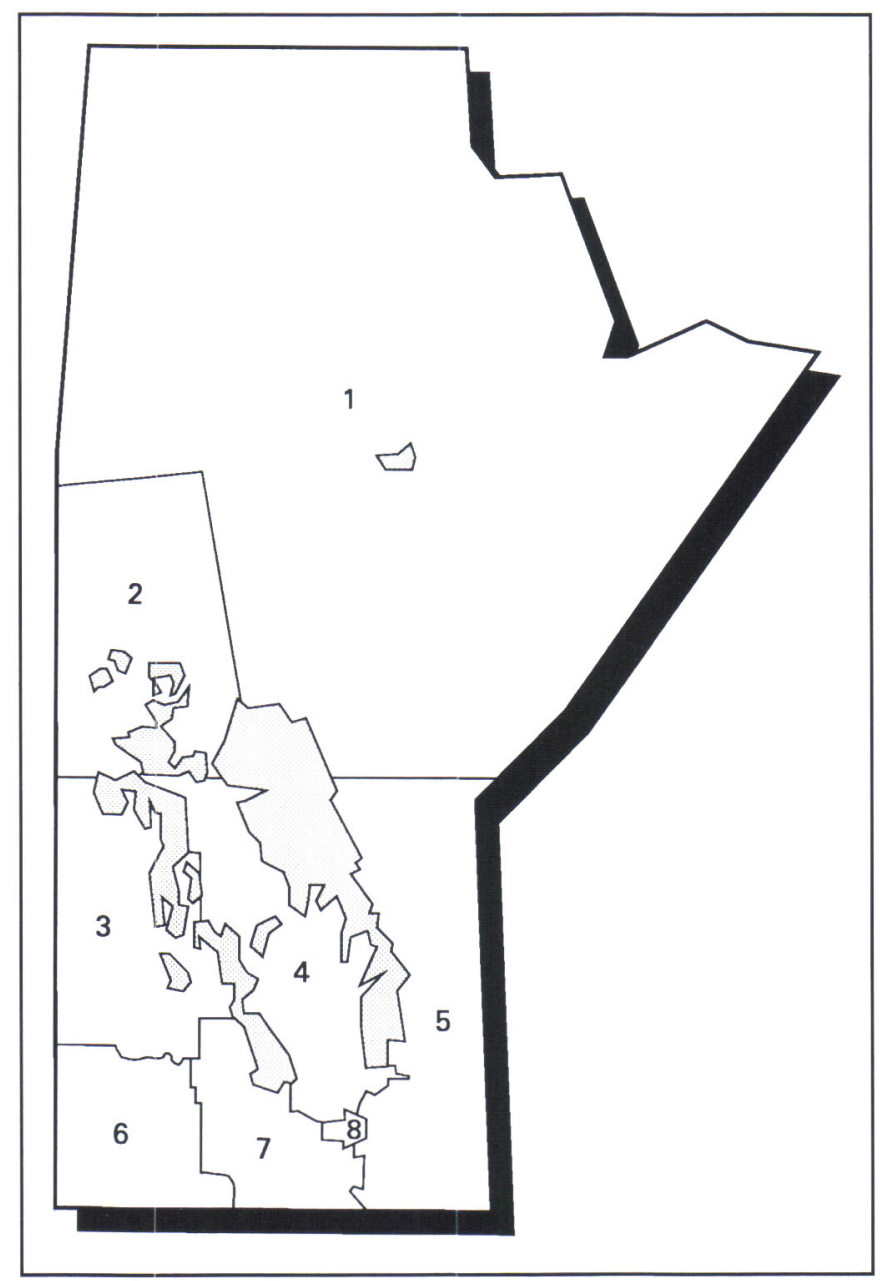

Figure 3: Regional Incidence of Pediatric Brain Tumors in Manitoba per 100,000 child-years. 1. Thompson: 5 (7): 2 . Norman: 3.4 (2): 3. Parklands: 4.3 (4); 4. Interlake: 4.1 (6); 5. Eastman: 5.2 (10); 6. Westman: 1.3 (3); 7. Central: 5.7 (12); 8. Winnipeg: 3.8 (45). (Number of cases per region is indicated in the bracket.) Distribution was relatively uniform with no significant differences among regions.

and validates our findings as truly population-based. The fairly modest tumor volume in many of our cases attests to an efficient tumor detection infrastructure, suggesting that our data are comprehensive. This contrasts with the report of the King Faisal Hospital where the advanced degree of disease at presentation may reflect a less rigorous tumor surveillance, with consequent distortion of epidemiology. ${ }^{5}$ The temporal profile of tumor incidence was also stable over the seven year study period, further substantiating the applicability of the data.

The unusually high ratio of male:female medulloblastoma cases (virtually 4:1) merits comment. Although there is a consistent male predominance of this tumor in various studies, it is unusual to elicit a gender ratio of greater than 2.5:1. However, although our figures indicate statistical significance $(p<0.049)$, our tumor tally for medulloblastoma was merely 14 , suggesting that we interpret this ratio with some degree of caution. This male proclivity for medulloblastoma may represent a genetic phenomenon, as the peak incidence predates the endocrinologic cues of puberty. ${ }^{17-18}$ Furthermore, environmental influences 
Table 2: Location and Histopathology of 89 Pediatric Brain Tumors. ( ) indicate clinical/radiological diagnosis only.

\begin{tabular}{|c|c|c|c|c|c|c|c|c|}
\hline Histology & $\begin{array}{c}\text { Cerebral } \\
\text { Hemisphere }\end{array}$ & $\begin{array}{l}\text { Lateral or } \\
\text { 3rd Ventricle }\end{array}$ & 4th Ventricle & Cerebellum & Brainstem & $\begin{array}{c}\text { Cranial } \\
\text { Nerves }\end{array}$ & Meninges & Total \\
\hline \multicolumn{9}{|l|}{ Glial Tumors } \\
\hline - anaplastic astrocytoma & 6 & & & 3 & 4 & & & 13 \\
\hline \multicolumn{9}{|l|}{ - subependymal giant } \\
\hline - ependymoma & 1 & 1 & 2 & & & & & 4 \\
\hline - choroid plexus & & $3(1)$ & 1 & & & & & 4 \\
\hline - mixed glioma & 2 & & 1 & & & & & 3 \\
\hline - glioblastomatous & 1 & & & & & & & 1 \\
\hline Neuronal & & 2 & & & 1 & 1 & & 4 \\
\hline Medulloblastoma & 1 & & 4 & 9 & & & & 14 \\
\hline Lymphoma & 1 & & & & & & & 1 \\
\hline Germ Cell Tumors & & 1 & & & & & & 1 \\
\hline \multicolumn{9}{|l|}{ Malformative Tumors } \\
\hline - craniopharyngioma & 6 & & & & & & & 6 \\
\hline - colloid cyst & & $1(1)$ & & & & & & 1 \\
\hline - hamartoma & 2 & & & & & & & 2 \\
\hline \multicolumn{9}{|l|}{ Neuroendocrine Tumors } \\
\hline - adenoma & 2 & & & & & & & 2 \\
\hline
\end{tabular}

would ordinarily be anticipated to be gender-blind, unless inherent genomic characteristics imparted a selective vulnerability of sex. Interestingly, male children suffer a disproportionately high incidence of many of the extracranial malignancies as well. This is particularly true for lymphoid tumors, where Hodgkin's disease dominates in males to a $p$ value of $<0.001 .{ }^{1}$ Birch has suggested that the maternal immunologic milieu may be an especially hostile environment for the male fetus, potentially promoting tumor induction. '

Our study population demonstrated an equal proportion of infra- and supratentorial lesions. In the subcategory from 5 14 years of age, however, the more traditional preponderance of infratentorial tumor is evident, a reflection of the incidence of medulloblastoma. The etiologic underpinnings of this disproportionate vulnerability of the child hindbrain to oncogenesis are unknown, and remain speculative. The cerebellum merely subtends $1 / 8$ th of the mass of the whole brain, and harbours fewer than half as many cells. ${ }^{2,19}$ It has been shown, however, that cerebellar growth from late fetal life through infancy greatly exceeds that of the cerebral hemispheres, possibly enhancing tumor induction. ${ }^{2,19}$ Involution of pluripotential blast cells may be relatively delayed in the hindbrain, creating a ready pool of cells with proliferative potential. The external granular layer of the cerebellum has also been demonstrated experimentally to be uniquely susceptible to the tumorigenic effect of viruses and, in fact, Farwell has reported an increase in the incidence of medulloblastoma in children of women treated with SV40-contaminated polio vaccine. ${ }^{20}$ Birch has emphasized that the early onset of many childhood tumors, coupled with an histology that is frequently embryonal, implies a causal interplay between prenatal and genetic factors in their genesis. ${ }^{1,21}$

The distribution of tumor histology in our patients was not markedly dissimilar from other reports, with the exception of the King Faisal Hospital study. ${ }^{5}$ The proportion of high-grade astrocytoma (16\%), however, is greater than some other reports, and may reflect the age parameters of our study. ${ }^{22.23}$ Our incidence of ependymoma confirmed the decremental temporal trend documented by Gilles et al., but we were unable to replicate their prediction of a relative burgeoning in the incidence of medulloblastoma. ${ }^{24}$

In conclusion, then, the relatively higher incidence rates determined by us likely reflect utilization of multiple data sources, allied with the liberal application of high-resolution imaging techniques. It is unlikely that our data represent a significant trend to a real increment in pediatric brain tumor incidence, although this has been suggested to be the case in adults. ${ }^{25.26}$ Our study indicates that a general population of one million will suffer approximately twelve childhood brain tumors in a single year. This is not a considerable case burden, and the statistic should streamline resource allocation as well as contribute to the determination of optimal manpower projections for pediatric neurosurgeons. It is quite striking that the highest incidence rates for pediatric brain tumors have been recorded in Sweden and Canada, countries characterized by highly developed universal health care schemes. The efficacy of such systems in disease surveillance is also reflected in the present study, by uniform regional case ascertainment, and the addition of one case defined postmortem. 


\section{ACKNOWLEDGEMENTS}

The authors gratefully acknowledge the cooperation and assistance provided to them in compilation of these data by the Departments of Medical Information (Audit and Research), the Operating Rooms of the Health Sciences Centre and the St. Boniface General Hospital, Winnipeg, Canada, and Winnipeg's pediatric neurologists, Drs. Seshia Shashikant and Fran Booth. Appreciation is extended to Drs. Cam Mustard, Manitoba Centre for Health Policy and Evaluation, Winnipeg, Canada, and Dr. Bob Tate, Biostatistics Consulting Unit, University of Manitoba, Winnipeg, Manitoba, for providing the demographic data and statistical evaluation, respectively. Dr. William Halliday, Department of Pathology (Neuropathology), University of Manitoba, reviewed the histopathological slides.

\section{REFERENCES}

1. Birch JM, Marsden HB, Swindell R. Incidence of malignant disease in childhood: a 24-year review of the Manchester children's tumor registry data. Br J Cancer 1980; 42: 215-223.

2. Lannering B, Marky I, Nordborg C. Brain tumors in childhood and adolescence in West Sweden, 1970-1984. Cancer 1990; 66: 604609.

3. Stiller CA, Bunch KJ. Brain and spinal tumors in children aged under two years: incidence and survival in Britain, 1971-1985. Br J Cancer 1992; 66: 550-553.

4. Mosso ML, Colombo R, Giordano L, et al. Childhood cancer registry of the Province of Torino, Italy. Cancer 1992; 69: 13001306.

5. Siqueira EB, Rahm B, Kanaan I, Jallu A. Brain tumors in pediatric patients at King Faisal Specialist Hospital and Research Centre. Surg Neurol 1993; 39: 443-450.

6. Warnick RE, Edwards MSB. Pediatric brain tumors. Curr Probl Pediatr 1991; 129-175.

7. Horm JW, Asire AJ, Young JL, et al. SEER Program: cancer incidence and mortality in the United States 1973-1981. Bethesda, MD, National Institute of Health Publication No. 85-1837, 1984.

8. Cancer Statistics Review 1973-1986. Bethesda, MD, National Institute of Health Publication No. 89-2789, 1989.

9. Sutherland GR, Florell R, Louw DF, Choi NW, Sima AAF. Epidemiology of primary intracranial neoplasms in Manitoba, Canada. Can J Neurol Sci 1987; 14: 586-592.

10. Preston-Martin S, Staples M, Farrugia H, Guiles G. Primary tumors of the brain, cranial nerves and cranial meninges in Victoria, Australia, 1982-1990: patterns of incidence and survival. Neuroepidemiology 1993; 12(5): 270-279.
11. Jumar R, Tekkok IH, Jones RA. Intracranial tumors in the first 18 months of life. Childs Nerv Syst 1990; 6(7): 371-374.

12. Hwang SL, Howng SL. An analysis of brain tumors in south Taiwan. Kaohsiung J Med Sci 1992; 8(12): 656-664.

13. Mueller BA, Gurney JG. Epidemiology of pediatric brain tumors. Neurosurg Clin N Am 1992; 3(4): 715-721.

14. Borch K, Jacobsen T, Olsen JH, Hirsch F, Hertz H. Neonatal cancer in Denmark 1943-1985. Pediatr Hematol Oncol 1992; 9(3): 209. 216.

15. Rorke LB, Gilles FH, Davis RL, Becker LE. Revision of the World Health Organization classification of brain tumors for childhood brain tumors. Cancer 1985; 56: 1869-1886.

16. Wilkin JR IIIrd, McLaughlin JA, Sinks TH, Kosnik EJ. Parental occupation and intracranial neoplasms of childhood: anecdotal evidence from a unique occupational cancer cluster. Am J Indust Med 199I; 19(5): 643-653.

17. Kuitjen RR, Strom SS, Rorke LB, et al. Family history of cancer and seizures in young children with brain tumors: a report from the Childrens Cancer Group (United States and Canada). Cancer Causes Control 1993; 4(5): 455-464.

18. Bondy ML, Lustbader ED, Buffler PA, et al. Genetic epidemiology of childhood brain tumors. Genet Epidemiol 1991; 8(4): 253267.

19. Dobbing J, Sands J. Quantitative growth and development of human brain. Arch Dis Child 1973; 48: 757-767.

20. Farwell JR, Dohrmann GJ, Flannery JT. Medulloblastoma in childhood: an epidemiological study. J Neurosurg 1984; 61: 657-664.

21. Sussman A, Leviton A, Allred EN, et al. Childhood brain tumor: presentation at younger age is associated with a family tumor history. Cancer Causes Control 1990; I(1): 75-79.

22. Geyer JR, Berger M. Central nervous system malignancies in children. NY State J Med 1990; 90: 601-608.

23. Duffner PK, Cohen ME, Myers MH, Heise HW. Survival of children with brain tumors: SEER Program, 1973-1980. Neurology 1986; 36: 597-601.

24. Gilles FH, Sobel EL, LeViton A, et al. Temporal trends among childhood brain tumor biopsies. The Childhood Brain Tumor Consortium. J Neurooncol 1992; 13(2): 137-149.

25. Desmeules M, Mikkelsen T, Mao Y. Increasing incidence of primary malignant brain tumors: influence of diagnostic methods. J Natl Cancer Inst 1992; 84(6): 442-445.

26. Larsen NS. Brain tumor incidence rising; researchers ask why. J Natl Cancer Inst 1993; 85(13): 1024-1025. 